\title{
Evaluating trust and shared group identities in emergent social learning processes in the Zambezi river basin
}

\author{
Caroline K. Lumosi ${ }^{1 凶}$, Claudia Pahl-Wostl ${ }^{1} \&$ Geeske Scholz ${ }^{1}$
}

Social learning in natural resource management is considered important for addressing complex problems by supporting multi-stakeholder interactions in problem framing and coconstruction of solutions. Despite the considerable progress in the social learning discourse, few scholars have empirically examined relational features in social learning interactions. Relational features such as trust and shared group identities are important for supporting engagement and interaction among actors. This study analyzed emergent social learning processes in transboundary river basin cooperation processes in the Zambezi basin. To do this, data was conducted through in-depth interviews with diverse actors, observations of participatory workshops, and review of documents on transboundary cooperation processes in the Zambezi basin. The study evaluated how trust and shared group identities shaped learning spaces (opportunities for interaction, deliberation and reframing) and in turn impacted transboundary river basin cooperation. The study found that trust and shared group identities had a crucial impact on learning spaces and in turn impacted transboundary river basin cooperation in the Zambezi basin. The results suggest that leveraging on trust and shared group identities can play a critical role in stimulating cooperation processes. However, it is not a guarantee for cooperation. This study highlights that structural-learning spaces such as institutions support the development of binding commitments and enduring shared practices. However, success of such institutionalization is strongly influenced by the prior development of trust and a shared social identity.

${ }^{1}$ Institute of Environmental Systems Research, Osnabrueck University, Barbarastrasse 12, 49076 Osnabrueck, Germany. ${ }^{凶}$ email: caroline.lumosi@uos.de 


\section{Introduction}

articipatory approaches are increasingly becoming popular in transboundary river management (Pahl-Wostl et al., 2007a; Watson, 2004). Participatory approaches account for system complexity, enhance ownership, representation and support responsibility among all actors (ibid). These participatory approaches often involve dealing with different stakeholder perspectives at multi-scales and within different institutional settings while addressing complex social-ecological issues (Pahl-Wostl et al., 2007a, 2008; Watson, 2004). Social learning has been used in participatory approaches to addresses such complexity by facilitating interactions among diverse actor groups, and at the same time developing actor's relational capacities to support a shared problem framing (Mostert et al., 2007; Pahl-Wostl et al., 2007a; Ridder et al., 2005). In transboundary river basin management, facilitated social learning processes can support diverse actors to better stimulate the building of a collective understanding in basin planning, resource use or in decision-making processes (Pahl-Wostl et al., 2007a; Ridder et al., 2005).

Social learning is a dynamic process that occurs through social interaction at different levels (Reed et al., 2010). Scholars have distinguished between the process of social learning (such as facilitated or emergent processes) and the outcomes of social learning (such as improved decisions, concerted action or transformed relationships) (Cundill and Rodela, 2012; Muro and Jeffrey, 2008; Pahl-Wostl et al., 2007b; PahlWostl and Hare, 2004). Despite the advancement in the social learning discourse, relational features in social learning processes have not received much attention from scholars (see de Vries et al., 2017; Romina, 2014; Sol et al., 2013; Van Bommel et al., 2009). More so, an understanding of relational features in emergent social learning processes is still lacking as most research is focussed on deliberative processes (Cundill and Rodela, 2012; de Vries et al., 2017; Eriksson et al., 2019; Herrero et al., 2019). Yet, such dynamics could greatly impact the process of social learning and the outcomes of learning (Berkes, 2009; Cundill and Rodela, 2012; Pahl-Wostl and Hare, 2004; Romina, 2014; Scholz and Methner, 2019; Van Bommel et al., 2009). For example, in a project investigating integrated management and sustainable use of natural land among farmers and nature conservation groups in the Netherlands, Van Bommel et al. (2009) find that social learning was hindered due to distrust. The stakeholders were not able to have an open dialog on the problem framing, as the farmers did not trust that the nature conservation groups would consider their views in problem framing. Such relational features impact on actors' interactions and ability to address resource management issues and engage in collective action.

This study contributes to the empirical research on social learning by addressing knowledge gaps concerning relational features in social learning processes. Based on a review of the natural resource management literature, we identified trust and identity as two relational features that shape social learning processes (Berkes, 2009; de Vries et al., 2017; PahlWostl and Hare, 2004; Romina, 2014; Sol et al., 2013). We use the concept of learning space (opportunities for interaction, deliberation and reframing) to evaluate social learning processes (Lumosi et al., 2019). We evaluate past emergent transboundary river basin cooperation processes in the Zambezi basin to understand how relational features shape learning spaces and in turn impact transboundary river basin cooperation processes. We ask "how does trust and shared group identity influence social learning processes and impact transboundary river basin cooperation processes in the Zambezi basin?" This research question is further elaborated through the following specific research questions: a. How do trust and shared group identities shape processes occurring within learning spaces in the Zambezi river basin?

b. How do learning spaces influence transboundary river basin cooperation processes in the Zambezi river basin?

This paper is organized as follows: we first introduce the conceptual framework, exploring the concept of learning space, trust and shared group identity. Next, we present our research methods and the empirical case. We then present results from the case study and a discussion. We end with our conclusions and address as well the broader relevance of our findings.

\section{Conceptual framework}

We reviewed literature on trust, social identity, communities of practice, and social learning to develop the conceptual framework used. The following section elaborates the conceptual framework in more details.

Relationship between social learning and learning space. Social learning in resource management can offer a way to integrate different knowledge, develop relational capacities or support perspective taking on issues (Ridder et al., 2005). In the natural resource management literature, there seems to be no consensus on how social learning is understood (Cundill and Rodela, 2012; Muro and Jeffrey, 2008). Various scholars have attempted to define social learning (see Daniels and Walker, 1996; Keen et al., 2005; Pahl-Wostl et al., 2007a; Reed et al., 2010; Rist et al., 2007; Schusler et al., 2003). Pahl-Wostl et al. (2007a) conceptualize social learning as a process that is embedded in a specific context and leads to specific outcomes. Keen et al. (2005) defined social learning as "the collective action and reflection that occurs among different individuals and groups as they work to improve the management of human and environmental interrelations" (Keen et al., 2005; p. 4). Keen et al. (2005)'s focus was on the deliberative process of multi-stakeholders debating on resource dilemmas and resource issues to bring about collective action through engaging in stakeholder platforms. Further, other scholars regard social learning as a process that is driven through deliberations, dialogues leading to joint action, common understanding or change in governance norms (Daniels and Walker, 1996; Pahl-Wostl and Hare, 2004; Rist et al., 2007; Schusler et al., 2003). Reed et al. (2010) argue that social learning may occur in organized participatory processes as well as in the absence of participatory processes, such as emergent processes. However, few scholars have analyzed social learning in emergent processes (Folke et al., 2005; Pelling et al., 2008). In an attempt to bring consensus on how social learning is defined, Reed et al. (2010: p. 6) define social learning as "a change in understanding that goes beyond the individual to become situated within wider social units or communities of practice through social interactions between actors within social networks." The definition put forward by Reed and colleagues has been widely cited in the natural resource management literature (see Cundill and Rodela, 2012). In relation to social learning outcomes, widely accepted categorization of social learning outcomes was put forward by Lebel et al. (2010). Social learning outcomes are grouped as: cognitive outcomes such as improved knowledge; relational outcomes such as improved relations and trust building; and normative outcome in terms of a change in norms and values (Baird et al., 2014; Lebel et al., 2010). In an attempt to bridge the gap in assessing social learning in deliberative and emergent processes, the concept of learning spaces is introduced (see Lumosi et al., 2019). Learning space is defined as an arena for interaction, deliberation and reframing (Lumosi et al., 2019). In this study we understand social learning 


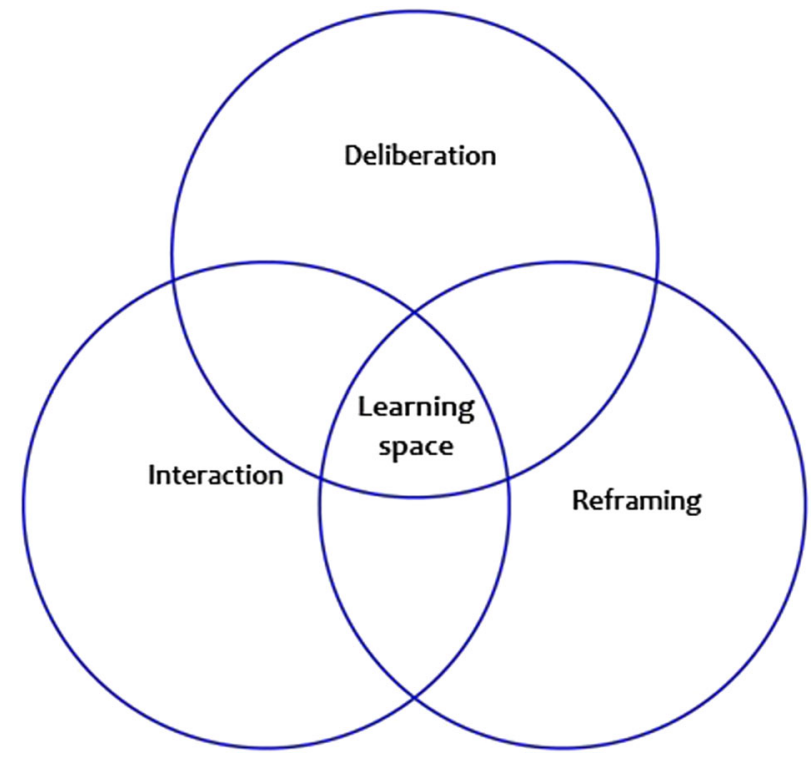

Fig. 1 Process of social learning. Shown as interlinkages of interaction, deliberation and reframing (source own).

as a dynamic process that occurs through social interactions and is situated in wider social units or communities of practice (Reed et al., 2010). We view social learning occurring in either deliberative processes (that require facilitation and often occur in participatory settings like workshops) or in emergent processes (that can be triggered by an external event, e.g., flooding events that lead to new ways of designing flood management systems) (Cundill and Rodela, 2012; Cundill and Harvey, 2019). In this study we evaluate emergent social learning processes.

We view social learning as a process that can have certain outcomes (Cundill and Rodela, 2012; Reed et al., 2010). We argue that social learning occurs in learning spaces (Lumosi et al., 2019), in which actors interact, deliberate and reframe issues and solutions (ibid). A learning space is defined as an arena for interaction, deliberation and reframing (Lumosi et al., 2019). Learning spaces are the interlinkage of interaction, deliberation and reframing that act as sparks for social learning (see Fig. 1). Evidence of learning spaces can be in the form of structurallearning spaces such as institutional structures and frameworks; physical-learning spaces such as forums where actors have an opportunity to interact and deliberate based on their interests; and process-learning spaces in which self-organized processes trigger actors to act and address a need (ibid). Learning spaces stimulate relational capacities among actor groups and foster negotiations of roles, problem framings or perspectives (ibid). Relational features such as trust and shared group identities could also influence processes occurring within learning spaces. In this study, we use the concept of learning space to evaluate sociallearning processes.

Relational features of social interactions: trust and shared group identity. Relational features are features that define how interpersonal or inter-organizational interactions evolve (Cundill et al., 2018). Social learning can be fostered or hindered by relational features such as trust or group identities (de Vries et al., 2017; Eshuis and Stuiver, 2005; Rodela, 2013; Suškevičs et al., 2019; Van Bommel et al., 2009). While trust is essential in actor interactions, it is rarely evaluated as a process feature (Boschetti et al., 2016). Likewise, collective identities which shape actors' interactions seldom feature in social learning assessments. This paper attempts to do address this gap by evaluating trust and group identities and assessing the drivers of trust and attributes of shared group identities in social interactions.

Trust. Trust shapes outcomes of learning processes by impacting on knowledge transfer and interpersonal relationships (de Vries et al., 2017; Pinto et al., 2009; Van Bommel et al., 2009). In addition, trust provides the basis for openness, transparency and facilitates a smooth interaction among actors (ibid). Trust can be defined as willingness to be vulnerable under conditions of risk and interdependence (Rousseau et al., 1998). In this study, we apply Hartman's (2002) model of trust to operationalize trust in three forms: competence trust, the belief in the ability to do the job; integrity trust, which means that one party assumes that the other will take care of their interest in a predictable way; and intuitive trust, which examines if the relationship feels right. We further operationalize competence trust as: ability, resources and power. By ability, we mean actors possessing ability through experience, knowledge, skills or information (Cook, 1999; de Oliveira and Rabechini, 2019; Nass, 1994). By resources, we refer to physical or social resources such as social relationships or culture (Bridge, 2009). By power, we mean decision-making power, power to shape the agenda, and domination power (Lukes, 2005). Integrity trust is conceptualized as transparency, accountability, participation and responsibility (Das et al., 2016; Engelbrecht et al., 2017; Karlsen et al., 2008; Pinto et al., 2009). Finally, we conceptualize intuitive trust as trust driven by perceptions that are aligned to ones' values, norms and attitudes (de Oliveira and Rabechini, 2019; Pinto et al., 2009).

Identity and shared group identities. Literature on identity has often focussed on internalization of identity within a selfstructure (Burke, 2004; Stryker et al., 2000) or how social context stimulates identities (Reicher et al., 2010; Tajfel and Turner, 1979; Turner et al., 1987) at individual or group levels, but less on how identities are reframed and co-constructed (Owens et al., 2010). Social identity theory focusses on identity formation within in-groups and out-groups (Tajfel, 1982; Tajfel and Turner, 1979). In social identity theory, groups are formed and founded on commonalities and members often conform in order to fit in (Tajfel, 1982). Groups may not always be homogeneous in nature as differences within a group does not take away from the group's sense of belonging (Jans et al., 2011). Groups can also be formed to achieve a common goal and in such cases, similarities of group members are not prerequisite for group formation, however, group characteristics are key in determining group outcomes (Jans et al., 2011). Thus, formation of group identities or shared identity of the group becomes key for understanding group outcomes. This requires an evaluation of group attributes and membership. Shared group memberships can facilitate trust (Neville and Reicher, 2011). It is important to understand the characteristics of such group membership as individuals negotiate shared group identities through their interaction and participation within the group (Wenger, 1998).

Scholars have shown that actors do not act on their own but are embedded in group practices, which shapes their identity (Handley et al., 2006; Harrington et al., 2008; Pahl-Wostl, 2006; Pahl-Wostl et al., 2007a; Wenger, 1998). In natural resource management such group practices could include: flood management practices, information sharing practices or decision-making practices. As actors actively participate in group activities they constantly shape their group identity (Pahl-Wostl, 2006; Wenger, 1998). Thus, participation of actors in group practices forms a key attribute to a group's shared identity. We evaluate group identities by assessing actors' membership and involvement in a practice. We use the concept of community of practice (Wenger, 1998). Communities of practice refer to a group of people with a 


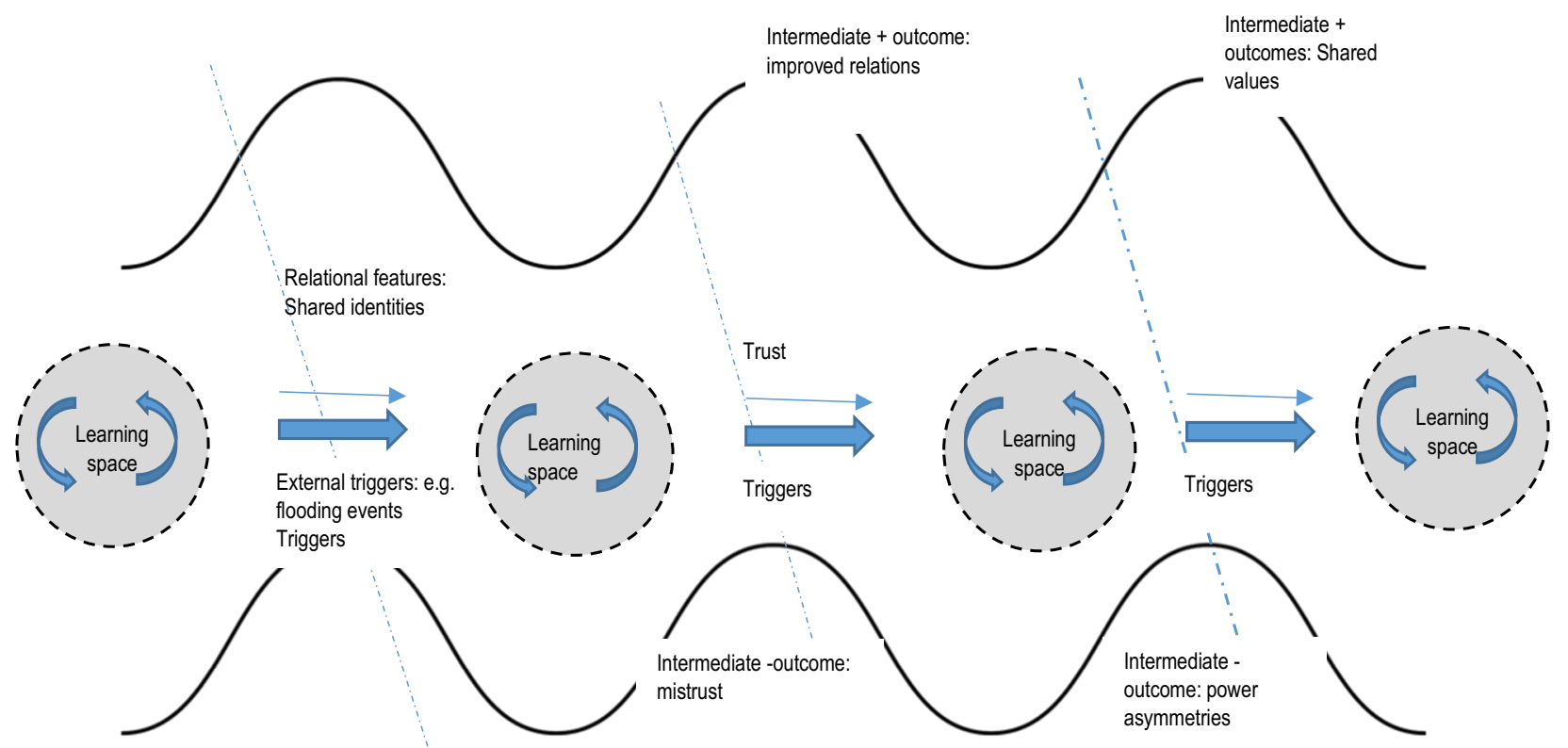

Fig. 2 Learning space and emergence of relational features. Shows how actors continuous develop interaction, deliberation, and reframing (learning space) triggered by relational features such as trust and shared identities that result in intermediate (positive and negative) outcomes at different stages of the process. This figure is not covered by the Creative Commons Attribution 4.0 International License. Adapted from Lumosi et al. (2019) and reproduced with permission of Elsevier Ltd; copyright (c) 2019 Elsevier Ltd, all rights reserved.

common interest concerning a certain practice and who learn to do it better by regularly interacting with each other (Wenger, 1998). The use of the community of practice lens moves away from looking at identity through self-structures or situations but rather as a collective and a basis for joint action (Owens et al., 2010). The aim of this study is not to study collective group action but rather to highlight how the attributes of shared identity trigger collective outcomes. To this end, the attributes of a shared group identity are conceptualized as members belonging to a joint enterprise, members taking part in a mutual engagement and members sharing a repertoire (Wenger, 1998). A joint enterprise involves members who are involved in joint activities and develop an accountability to the enterprise, for example, by belonging to a research group. Mutual engagement implies that actors take active roles in the community, for example, members could contribute to the research group by taking part in research related activities. Shared repertoire means members share certain skill sets, behavior, history, culture, styles, discourses, and concepts (ibid). Taken together, learning space, trust and shared group identities form the conceptual framework for our study. Figure 2 illustrates this relationship.

\section{Methods}

The analysis of this case study focussed on how the drivers of trust and attributes of shared group identities stimulated learning spaces and impacted transboundary cooperation, leading to the establishment of a river basin organization in the Zambezi basin.

Case study selection. In order to understand how trust and shared group identities influence learning spaces and transboundary river cooperation processes in the Zambezi basin, a case study approach was selected (Yin, 2014). According to Yin (2014), a case study approach supports an in-depth understanding of a phenomena in context by relying on multiple sources of data in order to triangulate the evidence. As the aim of the case study is not to provide representation to wider populations and thus not seeking generalization but rather to seek a deeper understanding of the phenomena. In addition, as this is a single case study, in order to support further external validity, depth of the study and analytical generalization to the theory, multiple case studies could be carried out including increasing the samples of stakeholders interviewed.

Transboundary basin cooperation practices were the phenomena under study within cases of transboundary river basin cooperation processes, while regional and national actors were the units of analysis. Transboundary basin cooperation processes in the Zambezi basin were selected as the main case for three reason. First, the basin has an active river basin organization (Zambezi watercourse commission-ZAMCOM) (Lautze et al., 2017). Second, the Zambezi basin has a long successful history of cooperation (ibid), hence providing a rich case for studying past emergent social learning processes. Third, we build rapport with basin stakeholders through an ongoing river basin management project, (Decision Analytic Framework to explore the waterenergy-food NExus) DAFNE. The DAFNE project analyze waterenergy-food nexus issues in transboundary river basins in the Zambezi basin and Omo basin. Through the DAFNE project that started in September 2016, the first author had the opportunity to interact with basin actors through face to face project meetings, email exchange and phone calls. Through these interactions, the first author build rapport with stakeholders in the basin. From these processes, the first author was invited to attend ZAMCOM organized meetings and conferences in 2017 from where interview data was collected.

The main case (transboundary basin cooperation processes) was analyzed in three phases. These include transboundary river basin cooperation processes occurring: between 1940s-1960s (phase 1), between 1970s-1980s (phase 2) and between 1990s-2017 (phase 3). A detailed description of these phases is explained in section "cooperation processes in Southern Africa and the Zambezi basin."

Data collection and data analysis. Based on the principles of a case study design laid out by Yin (2014) data was mainly collected through literature review of key documents and sites supported 
by key informant interviews, participant observations and informal conversations (See supplementary material Tables S1, S2, S3, S5, and section 3). Document reviews supported a better understanding of trust and identity evolution in the 1st, 2nd, and 3rd phases. Further, document reviews were important to provide a deeper understanding of processes that stimulated establishment of ZAMCOM. All documents reviewed were in English. In-depth interviews were especially important to understand all the three phases from actors who have been involved or participated in basin processes over time and to better support a deeper understanding of processes in the $3^{\text {rd }}$ phase. Participant observations of current basin meetings and informal conversations were important to get clarification of basin processes in the $3^{\text {rd }}$ phase especially after the establishment of ZAMCOM. Observation of basin meetings was relevant to practically assess if the recommendations agreed by basin actors are actually practiced in reality. Informal conversations were important to support narratives from the authors in an unstructured manner.

To get access to basin actors, the lead author participated in three face to face basin-wide meetings. These meetings included the Zambezi basin stakeholder forum (ZBSF), a joint project steering committee (JPSC) and the ZAMCOM Technical SubCommittee on Hydrology (ZAMSCOH) all held in Lusaka, Zambia in September 2017. The aim of these meetings was to deliberate with eight riparian states on transboundary river basin cooperation and basin-wide planning. Participation in these meetings enabled to build rapport among actors.

Once rapport was built, purposive sampling was used to select interviewees from the participants attending the three meetings mentioned above. Actors in the Zambezi basin were selected to meet the following criteria: (i) involved in basin management processes (ii) belonging to a community of practice and (iii) had key roles in basin management in their respective countries. The interviewed actors were drawn from the eight riparian states and regional bodies representing non-profit organizations and national government agencies. Eighteen in-depth reflective interviews were conducted (see supplementary material Section 2 and 3 ). The interviews were based on reflections of past transboundary processes and current basin processes and practices. All interviews were conducted face to face in Lusaka, Zambia (with the exception of one, conducted via skype). Actors from all riparian states were interviewed as follows: 1 Angola, 2 Botswana, 1 Malawi, 2 Mozambique, 3 Namibia, 2 Tanzania, 2 Zambia and 1 Zimbabwe. In addition, regional stakeholders were interviewed: 1 from Zambezi River Authority (ZRA) and 3 from ZAMCOM. Interviews were conducted based on the availability and willingness of actors to participate after agreeing to an informed consent. As a limitation of the study, the interviews conducted represented a small sample of the basin states as such future research could involve a wider sample in data collection.

Using in-depth reflective interviews participants were introduced to topics and allowed to discuss. The interviewer followed up with probing questions for clarification. The interviews reflected on cooperation processes in the basin and how these processes evolved. Participant observations aimed at understanding transboundary cooperation processes in terms of the issues and histories. Specifically, observations were used to understand how basin actors interact, deliberate and reframed basin issues, to support a better understanding of how trust (competence, integrity, and intuitive) and shared identities facilitated these interaction, deliberation and reframing processes. Ten hours of participant observations were recorded in three basin-wide meetings (ZBSF, JPSC, and ZAMSCOH). Informal conversations were held during tea/lunch breaks, as well as during field trips. Data from reports and strategy plans was collected to map out the history of river basin cooperation processes in the Zambezi basin (see supplementary material section 4).

All interviews and meetings were audio recorded after seeking informed consent from participants. Data from the interviews and meetings was transcribed and analyzed. We organized and coded the data using a data analysis software (MaxQDA). We used open coding and concept coding in three cycles. The coding process resulted in themes such as: cooperation shaping, trust building and identity markers. In the analysis process we compared and contrasted the emerging patterns in order to form themes and provide a deeper understanding of the dynamics of trust and shared identity in social-learning processes (Boeije, 2002) (see supplementary material section 5 and Table S4).

\section{Case: transboundary cooperation in the Zambezi basin}

The Zambezi basin. The Zambezi basin stretches over eight riparian states-Angola, Botswana, Malawi, Mozambique, Namibia, Tanzania, Zambia and Zimbabwe-and covers an area of about 1.3 million $\mathrm{km}^{2}$ while meeting the needs of about 40 million people in the basin (Lautze et al., 2017) (see Fig. 3). The Zambezi River is $2700 \mathrm{~km}$ long with an average surface runoff of $103 \mathrm{~km} 3$ (ibid). The surface area of countries within the basin varies with Zambia covering approximately a total area of $42 \%$ of the basin, Angola 19\%, Zimbabwe 16\%, Mozambique 12\%, Malawi $8 \%$ and $1 \%$ for Namibia, Botswana and Tanzania (ibid).

Water use among the basin countries varies depending on the geographic location in the basin, water availability or access to water. Only $20 \%$ of the surface water is exploited for economic gain such as in hydropower production (Malawi, Mozambique, Zambia and Zimbabwe), irrigation (all but mostly Malawi, Zambia and Zimbabwe), mining, industrial and domestic water supply (all) and fisheries (Malawi, Tanzania, Zambia, Zimbabwe, and Mozambique). The variance in large-scale water use is due to high costs related to large water infrastructure development, lack of investment and technical capacity for water resources management and lack of institutional mechanisms to enable cooperative decision-making in transboundary investment at the basin level (ibid). Cooperation on use of basin resources has in the past been a driving force for trade, regional integration and economic growth among southern African states (Saruchera et al., 2017). For example, cooperation on the Kariba dam (Zambia and Zimbabwe), navigation on Lake Nyasa/Malawi linking Malawi, Tanzania and Mozambique as well as ferry crossing and navigation in Lake Kariba used for transport, fisheries and recreation activities between Zambia and Zimbabwe (Lautze et al., 2017).

Cooperation processes in Southern Africa and the Zambezi basin. Southern African states have a long history of cooperation around trade and regional integration (Saruchera et al., 2017). Cooperation processes in the Zambezi basin can viewed in three phases. Phase 1 (1940s-1960s) cooperation was characterized by treaties surrounding colonial agreements, and development agreements for trade and hydropower. During this phase, basin states were still colonized, thus, were united through liberation wars. Phase 2 (1970s-1980s) cooperation was based on developmental priorities of the independent basin states (7 out of 8 basin states were independent). In this phase, the Southern African Development Coordinating Conference (SADCC) was established (later transformed to Southern Africa Development Community, SADC in 1990) to steer regional integration in southern African states (Saruchera et al., 2017). Cooperation agreements were based on water and electricity allocation on the Kariba dam, flood 


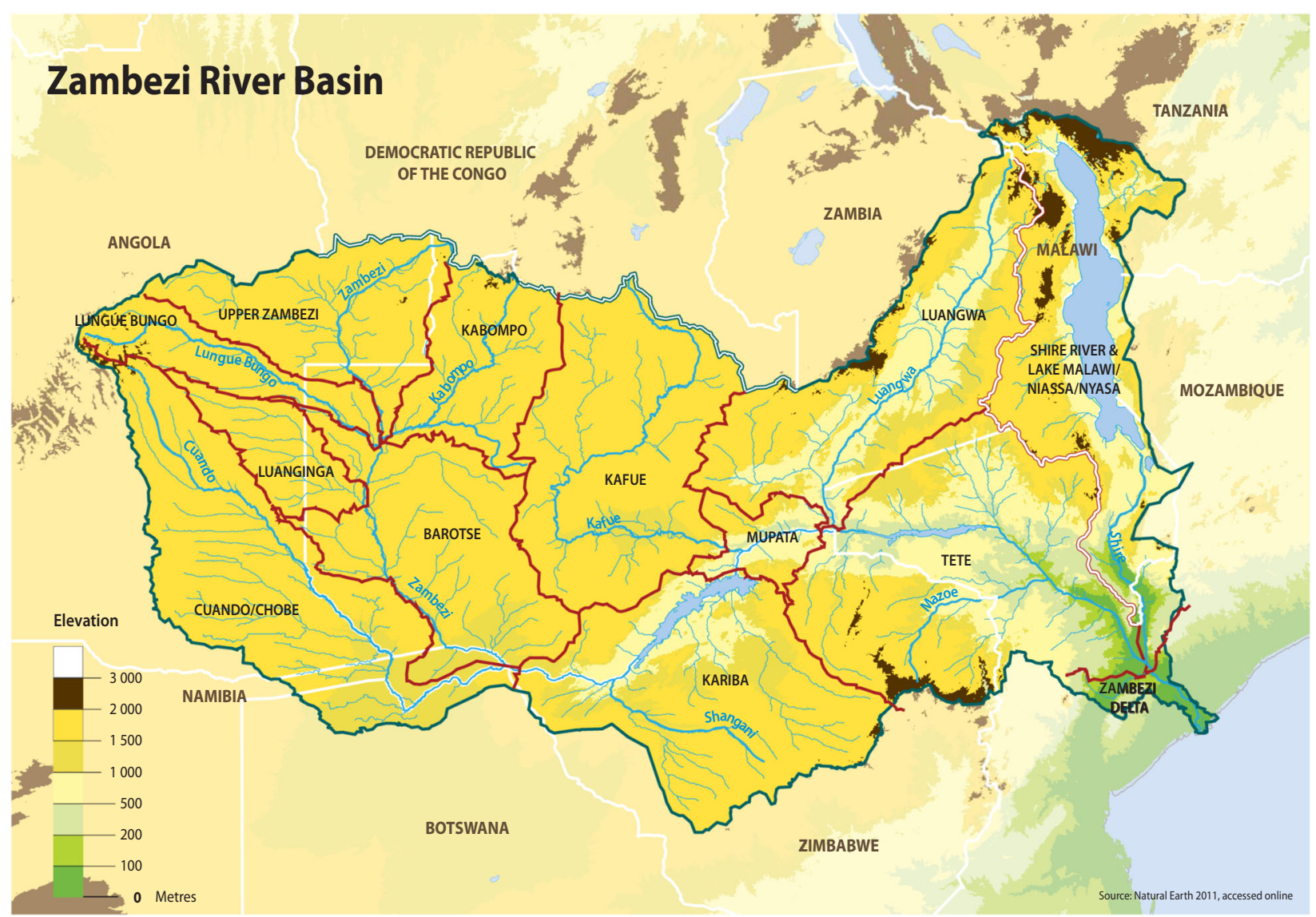

Fig. 3 Map of the Zambezi basin. Showing all the eight riparian countries, Source: GRID-Arendal https://www.grida.no/resources/5207. This figure is not covered by the Creative Commons Attribution 4.0 International License. Reproduced with permission of GRID-Arendal; copyright (C) GRID-Arendal, all rights reserved.

management, or environmental sound management of the Zambezi River (also known as ZACPLAN, Zambezi river basin action plan). Phase 3 (1990s to 2017) cooperation focussed on economic and environmental priorities and strategic management of the Zambezi basin. This included the implementation of the ZACPLAN, which facilitated incorporation of the Zambezi watercourse commission in 2004 (ZAMCOM) (Ibid).

In 2004, ZAMCOM agreement was signed by seven states (Angola, Botswana, Malawi, Mozambique, Namibia, Tanzania, and Zimbabwe) and ratified in 2011. The ratification process took long due to further consultation at the national level among some member states such as Zambia (Lautze et al., 2017). Zambia signed and ratified the ZAMCOM agreement in 2013 and Malawi is in the process of ratifying the agreement (Saruchera et al., 2017; ZAMCOM website). ZAMCOM was formed to coordinate equitable and reasonable utilization and management of water resources of the Zambezi basin (Lautze et al., 2017). Management in the Zambezi basin is coordinated through committees and forums. These include: ZBSF, coordinating basin-wide stakeholder interaction; JPSC, coordinating joint development projects; ZAMSCOH, providing technical advice on hydrology to decision makers; Joint Operations Technical Committee (JOTC), coordinating dam synchronization and hydrological flow; and ZAMCOM Technical Committee (ZAMTEC), which provides technical advice to the council of ministries. Table 1 below summarizes cooperation processes in the region over the years. In this study, we focus on two transboundary basin cooperation processes: (a) regional cooperation among states, and (b) basin management (e.g., data sharing; joint planning, development and decision-making).

\section{Results}

We combined data from interviews, reviewed documents, observations and informal conversations to construct the narrative highlighted in the results section.

How trust and shared identities evolved in transboundary cooperation processes in the Zambezi basin. The analysis from the document reviewed and stakeholders interviewed indicate that trust and shared identities among actors in the Zambezi basin were initially embedded in cultural and historical connections, and that these connections emerged prior to collaboration processes on joint water agreements. Data from the documents reviewed showed that, in the early years (1940s to 1960s), collaboration, trust and a sense of identity among southern African countries was stimulated by active participation in political liberations from colonial masters, commitment to regional integration and economic development and an alignment to similar cultural values (such as the collectivism value of Ubuntu ${ }^{1}$ ). Prior to colonization that occurred in southern African countries, these states existed as one region and traditionally traded and collaborated with each other. Also, stakeholders interviewed acknowledged the common basis of collaboration on water processes was founded on mutual trust among actors and engagement in joint processes within the southern Africa region. 
Table 1 Drivers of cooperation in the southern African region and the Zambezi basin over time.

\section{Time frame}

Phase 1 1940s-1960s

Phase 2 1970s-1980s

Phase 3 1990s-2017
Drivers of cooperation in southern Africa region and the Zambezi basin

Colonial priorities such as development of resources for trade Independence from colonial powers

Development of the independent basin states

Support from SADCC (later SADC)

Environmental sound management of the basin

Need for river basin organization (RBO)

Management of river basin resources (ZAMCOM)

Equitable utilization and sharing of river basin resources

Source: authors, from reviewed documents and interviews.

Stakeholders reflect on the growth of trust and sense of shared identity in the basin:

“... after all we are one [...] our culture also binds us together, we have an element that binds us together besides water, and also being members of SADC" (Respondent 16, national actor, Botswana, senior expert)

“...member states coming together has some historical bearing, because we had a common threat of apartheid, the southern states like Zambia took in refugees [...]. Member states started collaborating long before [...] we have similar historical background, then we are the Bantu language group, [...] our language is similar" (Respondent 12, regional actor, ZAMCOM, senior expert).

Analysis from documents reviews showed that in 1970-1990, in order to reduce the dependency of Southern African states on South Africa (which was going through apartheid), SADC was formed. In addition, SADC was formed to support national political liberation, regional integration and economic liberation (SADC website). These collaborations fostered a sense of shared identity. During this period, southern African states fostered a sense of shared identity through the bilateral agreements, such on utilization of water resources in the Kariba dam between Zambia and Zimbabwe (at the time known as Northern and Southern Rhodesia). In the early 1980s southern African states collaboratively participated in the inauguration of the Southern African Development Coordination Conference (SADCC) whose main aim was to support regional integration and economic liberation for southern African states. SADCC later was transformed to SADC in 1992, to coordinate development, economic growth and regional integration.

Data analysis from documents reviews and stakeholder interviews shows that trust and a sense of shared identity among actors was rooted in a common vision for environmental protection among southern Africa actors, later on, trust was further developed through institutional structures such as ZAMCOM. In later years (late 1980s-2000s), reviewed data shows that as most southern African states became independent, they began to cooperate on shared watercourses. For the Zambezi basin, basin actors incorporated ZACPLAN in 1987 (ZACPLAN) (also known as agreement on the action plan for the environmentally sound management of the common Zambezi river system). ZACPLAN was a platform for promoting regional cooperation on shared water resources and for resolving conflicts among basin actors. However, ZACPLAN implementation needed to be anchored within a regional framework as the Zambezi basin rans through several southern African states. This led to SADC member states deliberating on guidelines to coordinate shared watercourses within the SADC region. The first discussions on shared watercourse in the SADC region took place between 1994/1995 and later a revised protocol was developed in 2000 and ratified in 2003. The SADC protocol on shared watercourses provided a framework to support coordinated management of watercourses in the SADC region such as the Zambezi basin, thus, creating a sense of shared identity among southern Africa states as states actively participated to incorporate the protocol. Note that, The SADC revised water protocol would later stimulate further basin cooperation processes beyond just the Zambezi basin. It was thus easier for basin actors to implement ZACPLAN after incorporation of the SADC protocol. Implementing ZACPLAN by basin actors deepened the shared vision in basin management. Through implementing ZACPLAN, the need for a coordinating body arose that stimulated deliberations to incorporate the Zambezi watercourse commission, ZAMCOM (established in 2004). Through ZAMCOM, basin actors shared a common goal in river basin management and developed shared practices in basin management, thus deepening trust relations and the sense of group identity. Stakeholders interviewed corroborated with these findings, a regional actor reflects on this process:

"There are several things that helped to build confidence and trust. Way back under the Zambezi Action Plan Project 6, Phase II (ZACPRO 6.2) project there was a program called the secondment programmme, which brought staff from the riparian state to work at the $\mathrm{ZACPRO}^{2}$ and they would be working together and sharing information" (Respondent 4, regional actor, ZAMCOM, senior expert)

In addition, through ZAMCOM, basin actors were able to deliberate and develop guiding frameworks on key issues in the basin. Such as on use of basin resources [through the Agreement on the establishment of the Zambezi Watercourse Commission, 2004], on sharing data and information [through the Rules and procedures for sharing of data and information related to the management and development of the Zambezi watercourse (2016)] or on sharing information on natural calamities like floods [through the Transboundary Water Management in SADC Program. Dam synchronization and flood releases in the Zambezi river basin project, 2011]. Participation of basin actors in these processes fostered interdependency and a sense of responsibility towards each other, thus fostering a sense of trust and shared identity.

Dynamics of trust and shared group identities shaping processes occurring within learning spaces in the Zambezi basin. Data analysis from document reviews and stakeholder interviews shows that regional cooperation among basin actors was fostered through institutions such as SADC, ZACPLAN, and ZAMCOM, which built trust and fostered a sense of shared identity. However, trust relations among actors and the sense of group identity evolved and was triggered by different factors. Documents 
reviewed showed that with the incorporation of SADC, there was a need for regional collaboration on the use and management of natural resources such as the Zambezi basin. SADC triggered trust relations by providing a framework to guide deliberation on use of common resources in southern African states among basin actors (such as through the SADC revised water protocol). However, prior to establishment of ZAMCOM, there was a need for basin states to develop their own economies after independence. Data from documents reviewed shows trust relations and the sense of group identity during this phase was affected as basin states felt states were not fully transparent with each other on their national interest and priorities versus the regional priorities. This led to conflicting national versus regional priorities as states tried to maintain their sovereignty, thus hampering interactions among basin states and slowing down key decision processes. For example, Zambia was concerned that participating in regional cooperation by signing the ZAMCOM agreement would compromise its sovereignty, which is linked to its geographical position in the basin (i.e., $42 \%$ area) and autonomy and lead to delay in implementing its national development plans. Thus, Zambia developed a "wait and see" attitude, leading to delaying incorporation of ZAMCOM (deliberations began in the 1980s, and later put on hold due to missing regional legal tools for watercourse management in the SADC region, deliberations resumed and were concluded in 2004). The "wait and see" attitude impacted transparency and accountability among basin states causing a strain on integrity trust and intuitive trust among basin actors. However, it is important to note that while Zambia had initial concerns regarding signing the ZAMCOM agreement, it is currently participating in ZAMCOM activities in good faith (see Saruchera et al., 2017). In addition, Zambia acknowledges that the best way to resolve their concerns is in actively participating through ZAMCOM and leaving room for dialog. One stakeholder from Zambia affirmed this statement:

I can mention that Zambia delayed rectifying the ZAMCOM agreement specifically because it has certain concerns, for example if you say the water will be shared equitably but it is the details of what this mean, those details need to be resolved. [...] the will is there but maybe the pace at which we are moving is slow, I think there is room for improvement in terms of ZAMCOM'S capacity, so far I think we can trust them [ZAMCOM] [...] generally I would say there is trust among member states (Respondent 10, national actor, Zambia, Technical expert)

Stakeholders interviewed confirmed that trust dynamics are still evolving as actors are building structures to facilitate collaborative processes and develop effective and transparent systems. For example, issues of transparency regarding sharing of data and timely disbursement of information to downstream countries during the rainy season were raised during basin meetings and stakeholders noted that such issues delay and hamper cooperation processes. Mistrust, transparency issues, hording information and data, and "hiding" information on basin activities were reported to hinder trust and proper basin planning. Two actors reflect on this:

"...Zambia think that the Zambezi belongs to them that is the problem, it is very difficult to share information with Zambia, [...] they [Zambia] think that they are the ones that should own the whole basin, but [they are] still a problem." (Respondent 14, national actor, water sector, Mozambique, Technical expert)

As can be seen from the above example, transparency issues are noted between upstream countries such as Zambia and downstream countries such as Mozambique when it comes to timely sharing of information and data such as stream flow and rainfall data. In addition, stakeholders also acknowledged the lack of harmonized data sharing formats also lead to delays in sharing data. In addition, stakeholders mentioned transparency regarding the benefits and costs associated with equity in regional cooperation was still unclear and needed to be openly addressed. One actor states:

"While the benefits of cooperation at the regional level are emphasized, am still not seeing what they are [and] [...] how they benefit individual countries [...] there is this silent competition" (Respondent 19, national actor, Zambia, senior expert).

The results of the document reviews, interviews and observations reveal that a breakdown of trust among basin actors impacted on transboundary cooperation processes. Data from interviews and observations of basin meetings showed that basin actors are still learning to trust each other. For example, stakeholders in the observed meetings expressed the need for effective basin planning, clarity on the principle of equitable utilization of resources, and on the issue of water allocation and consideration for environmental flows. A stakeholder in the ZBSF meeting mentioned:

"The capacity [of ZAMCOM] is there but there is still room for improvement because I observed that they might not have the legal power to intensify what is stipulated in the agreement or mandate." (Respondent 6, National actor, Namibia, senior expert)

Throughout the ongoing stakeholder meetings that were observed, it was noted that that trust, and power asymmetries were still evolving and were based on transparency issues around information and data sharing, as well as questioning the technical capacity of the coordinating body (ZAMCOM) to effectively conduct its mandate. While stakeholder interviewed mentioned that such issues could be raised and addressed within ZAMCOM, they acknowledged ZAMCOM's capacity still needs to be strengthened. Table 2 summaries dynamics of trust and identity in the basin over time.

Processes occurring within learning spaces and how they shaped transboundary basin cooperation in the Zambezi basin. Data analysis from document reviews and stakeholder interviews show that while deliberations on incorporation of ZAMCOM took a long time (over 30 years) and as a result impacted on the initial trust built, over time, ZAMCOM has acted as a bridge to foster trust and a sense of group identity among actors. Incorporation of ZAMCOM redefined a new sense of identity exemplified through the common vision of sustainable basin management. Through ZAMCOM, basin actors are accountable to each other and mutually engage in ZAM$\mathrm{COM}$ management processes such as through the Zambezi basin stakeholder forum. ZAMCOM provides structures and guidelines to guide, harmonize, coordinate, and support actors to manage activities and projects in the basin, thus further strengthening trust relations. These guidelines are in form of rules, protocols or regulations enforced through ZAMCOM to the member states who are bound to ZAMCOM regulations (as of 2013 all member states have signed and ratified the ZAMCOM agreement, Malawi is in the process of ratifying the agreement; source ZAMCOM website).

The results of the document reviews and interviews showed that establishment of protocols and regulations further strengthened trust relations and provided a basis for better coordination of basin cooperation processes. Further data showed that, coordination of basin practices and processes has been made easy through the enforcement of protocols and regulations. Protocols such as "the rules and procedures for sharing data and information related to the management and development of the 
Table 2 Evolution of trust and shared identities in the Zambezi basin over time.

\begin{tabular}{|c|c|c|}
\hline $\begin{array}{l}\text { Phase } 1 \text { (1940s-1960s). } \\
\text { Characterized by, interaction by southern } \\
\text { African states }\end{array}$ & $\begin{array}{l}\text { Phase } 2 \text { (1970s-1980s). } \\
\text { Characterized by, deliberation and reframing of } \\
\text { problems/ issues in the basin }\end{array}$ & $\begin{array}{l}\text { Phase } 3 \text { (1990s-2017). } \\
\text { Characterized by, deliberation, reframing and } \\
\text { collective management }\end{array}$ \\
\hline Drivers of trust & Drivers of trust & Drivers of trust \\
\hline \multirow{3}{*}{$\begin{array}{l}\text { Competence trust } \\
\text { Limited decision power as states are still } \\
\text { colonized }\end{array}$} & \multirow{3}{*}{$\begin{array}{l}\text { Competence trust } \\
\text { Independent states could make decisions } \\
\text { Missing joint legislative frameworks }\end{array}$} & Competence trust \\
\hline & & Institutions developed \\
\hline & & $\begin{array}{l}\text { Participation of actors in basin processes } \\
\text { Incorporation of ZAMCOM }\end{array}$ \\
\hline \multirow{4}{*}{$\begin{array}{l}\text { Integrity trust } \\
\text { States committed to regional integration } \\
\text { States participating in war liberation } \\
\text { Participation in bilateral agreements }\end{array}$} & \multirow[t]{4}{*}{ Integrity trust } & Integrity trust \\
\hline & & Incorporation of ZAMCOM supports \\
\hline & & accountability \\
\hline & & $\begin{array}{l}\text { Equal participation of actors } \\
\text { Clear structures to handle conflicts }\end{array}$ \\
\hline \multirow{3}{*}{$\begin{array}{l}\text { Intuitive trust } \\
\text { Similar culture and political struggles } \\
\text { Positive attitude towards integration }\end{array}$} & \multirow[t]{3}{*}{ Intuitive trust } & \multirow{3}{*}{$\begin{array}{l}\text { Intuitive trust } \\
\text { New group norms formed (e.g., on data } \\
\text { sharing) }\end{array}$} \\
\hline & & \\
\hline & & \\
\hline \multirow{4}{*}{$\begin{array}{l}\text { Attributes of shared group identities: } \\
\text { Joint enterprise } \\
\text { Colonial rule in southern African states }\end{array}$} & Attributes of shared group identities: & \multirow{4}{*}{$\begin{array}{l}\text { Attributes of shared group identities: } \\
\text { Joint enterprise } \\
\text { - SADC } \\
\text { - ZAMCOM committees and forums }\end{array}$} \\
\hline & Joint enterprise & \\
\hline & SADCC \& SADC & \\
\hline & ZACPLAN & \\
\hline \multirow{6}{*}{$\begin{array}{l}\text { Mutual engagement } \\
\text { War liberation movements } \\
\text { Regional integration } \\
\text { Shared repertoire } \\
\text { Shared collectivism culture }\end{array}$} & Mutual engagement & \multirow{3}{*}{$\begin{array}{l}\text { Mutual engagement } \\
\text { - Actors participate in ZAMCOM meetings, } \\
\text { forums and other COPs }\end{array}$} \\
\hline & Implementation of ZACPLAN & \\
\hline & Deliberations on a RBO & \\
\hline & Shared repertoire & Shared repertoire \\
\hline & Shared collectivism values & New skills in basin management \\
\hline & Shared histories & New identities and histories \\
\hline
\end{tabular}

Zambezi watercourse" and "the procedures for notification of planned measures" supports information sharing, learning, and exchange sessions among basin actors. One national actor reflects on the impact of the data sharing protocol in his work:

"...the water sharing protocol that was signed by the ministers last year says all member countries must share data, [...] before we had problems getting data especially during the rainy season, if I request for data, [from country $\mathrm{x}$ ] they could say no $[\ldots]$, but now we have a signed protocol signed by the ministers, so if I request for data through $\mathrm{ZAMSEC}^{3}$ to the specific countries, they cannot deny me anything because of this protocol, which is adhered to ..."(Respondent 7, national actor, Namibia, Technical expert).

The interviews showed that ZAMCOM rules, ZAMCOM forums and committees facilitate easier actor participation such as in joint planning processes, thus creating a sense of group identity. For example, the ZBSF provides an arena for basin actors to meet annually to deliberate on basin management matters. Also, through ZAMTEC, actors are able propose rules to facilitate equitable and reasonable use of the Zambezi basin thus providing a space to learn, exchange and streamline joint planning and decision-making. One regional actor notes:

"sharing of information is championed, [by ZAMCOM], there is strong emphasis to continue to share information, [...] our team [at Zambezi River Authority, ZRA] has accommodated [ZAMWIS] system in our office, we are trying to use the system to enhance our activities in ZRA $[\ldots]$ through the joint operations technical committee, dam operators get information to help synchronize activities. [...] joint planning is relevant for synchronizing dam operations in the basin." (Respondent 2, regional actor, Zambezi River Authority, ZRA, Technical expert)
Further stakeholders interviewed indicated that having ZAMCOM as a coordinating body not only supports coordination of basin activities but also supports building of professional relationships and provides platforms for multi-actor participation thus strengthening actors' sense of group identity. Further, stakeholders noted that the ZAMCOM governing structure (the council of ministries, the highest decision-making organ in ZAMCOM) supported by a rotational leadership structure among the eight riparian states has helped to create transparency and accountability among all the member states, as each member state is given a chance at leading the council of ministries, thus fostering trust. Table 3 below summarizes the different timeframes, learning spaces and social-learning outcomes over time in the Zambezi basin.

\section{Discussion}

Our results show that trust and shared group identities are interrelated and influenced processes that occurred within learning spaces in the Zambezi basin and shaped transboundary river basin cooperation. Trust is critical in social learning and is the basis for collective action, cooperation and learning (Leeuwis, 2000; Van Bommel et al., 2009). Our findings show that trust evolved in three phases. In the first phase (1940s-1960s), attributes of shared group identities were based on shared collectivism culture, mutual engagement in war liberation movements and desire for regional integration, which facilitated trust relations. In the second phase (1970s-1990s), drivers of integrity trust and competence trust were seen as structurallearning spaces (such as SADCC, ZACPLAN). Structural spaces provided space for actors to engage and deliberate on joint river basin processes thus providing a platform for accountability, participation and commitment among actors. In the third phase (1990s-2017), attributes of shared group identities were fostered as physical and structural-learning spaces (such as ZAMCOM rules and ZAMCOM forums) developed, which lead to actors developing new shared 
Table 3 Learning space and social-learning outcomes in the Zambezi basin over time.

\begin{tabular}{|ccc} 
Timeframes & $\begin{array}{l}\text { Learning space: processes and key issues that stimulated interaction, deliberation } \\
\text { and reframing in the Zambezi basin }\end{array}$ & $\begin{array}{l}\text { Social-learning outcomes in the } \\
\text { Zambezi basin }\end{array}$ \\
\hline 1940 s-1960s & Need for independence & Improved relations among states \\
& Need for integration of trade and joint management of resources & Deliberations on formation of SADC \\
1970s-1980s sADC founded through SADCC \\
& Need for joint framework for river basin management & Deliberations on instituting a RBO begin (i.e., \\
& Need for and structure of RBO & ZAMCOM) \\
1990s-2017 & Deliberations on regional vs. national interests & ZAMCOM agreement finalized \\
& Pre ZAMCOM & ZAMCOM operational with functional \\
& Need for environmental sound management of the basin & committees and forums \\
& Deed to institutionalize ZAMCOM sharing protocol finalized \\
& Need for equitable resource management & Protocol on notification of planned \\
Need for protocols to structure shared water resources & measures finalized \\
Post ZAMCOM & Need for clarity on use of resources and information and data sharing among states & \\
Need for resolving conflicts and power dominances among states &
\end{tabular}

identities based on actors' commitment and involvement in ZAMCOM.

Further, our study shows that shared group identities fostered trust relations among actors and impacted on how actors interacted, deliberated and reframed processes. In the Zambezi basin, we find that in the first phase (1940s-1960s) cultural values and participation in political liberations stimulated intuitive trust, which was critical for facilitating interactions among actors. This later paved the way for the building of integrity trust as actors build structures to support transparency and accountability, as well as participation in basin processes. Later, competence trust developed as actors gained power, resources and the ability to steer basin management processes such as through ZAMCOM. de Oliveira and Rabechini (2019) also find that trust relationships in stakeholder management processes evolved from intuitive trust to integrity trust and finally to competence trust. We find that the building of trust (from intuitive to integrity and to competence trust) requires a sense of shared group identity that can be found in long processes and pre-existing connections within groups (Eriksson et al., 2019). Our results confirm studies that show that shared identities are critical for fostering trust among groups (Neville and Reicher, 2011). While intuitive trust stemmed from cultural norms and integrity trust was built on actor's joint participation and commitment to supporting regional integration, competence trust was affirmed through institutional structures in basin processes. Lacey et al. (2018) also find that values, cultural, social norms and historical association between parties, impact on trust development over time.

Our study further shows that a decline in trust affected processes occurring within the learning space and thus affected social learning processes. In the second phase, a decline in trust among actors emerged from transparency issues and power dominance, which delayed deliberations on the formation of ZAMCOM, thus, hindering learning and hampering transboundary cooperation processes. Similarly, Van Bommel et al. (2009) finds that negotiation processes between farmers and natural resource actors stagnated due to distrust and power asymmetries. Rebuilding trust among actors through a structural-learning space such as ZAMCOM played a role in facilitating further interactions, deliberations and reframing of basin management processes. As de Vries et al. (2017) argue, trust develops in interactions and being aware of what triggers trust and distrust in learning interactions could open up the space for knowledge sharing, production and co-creation among various actors in water governance. Structural-learning spaces such as ZAMCOM were crucial in facilitating learning among actors by providing structures and platforms for stakeholder participation and engagement in basin processes.

Our results show the relevance of fostering environments in which shared group identities are nurtured and leveraged on to support collective goals. We found that having a sense of shared identity nurtured in long-term processes stimulated intuitive trust among actors. Through SADC, member states developed shared group identities through regional integration processes. Cooperative norms and values of interconnectedness, interdependency, mutual respect and responsibility among states were critical in fostering mutual engagement and shared group identities among actors at regional and national levels. In addition, active participation in developing shared goals in ZAMCOM enforced shared identities and reinforced integrity trust. This created a common ground for stakeholders to address conflicts and engage in river basin cooperation processes thus stimulating competence trust. In summary, trust among basin states was built over time and included activities such as transparency in data and information sharing as currently supported by article 15 and 16 of the ZAMCOM agreement, participation of all member states in basin planning and cooperation processes, as supported by article 14 of the ZAMCOM agreement or in addressing power asymmetries through the equitable principle in article 13 of the ZAMCOM agreement. This interaction can be illustrated in Fig. 4 .

In the Zambezi basin, our study shows that processes occurring within learning spaces were crucial in fostering social learning and in turn transboundary cooperation. Process-learning spaces occurred as the need for states to self-govern, trade and integrate grew. Intuitive trust and shared group identities were then catalysts for actors to further interact and deliberate on collective management of the Zambezi basin. Structural-learning spaces such as ZACPLAN and later ZAMCOM provided the framework to guide actors' interactions, address conflicts, guide cooperation processes, steer deliberations and support reframing of key issues, as actors developed integrity and competence trust. Physicallearning spaces such as the ZBSF were critical to support regular stakeholder participation. Lumosi et al. (2019) argue that learning spaces provide an underlying fabric for reframing and social learning. ZAMCOM acted as a learning space for basin actors to engage in deliberations on transboundary cooperation issues in the basin. Other studies have shown that building of trust among stakeholders through having structures and processes with clearly defined rules, roles and mechanisms for stakeholder interaction and decision-making fosters social learning (de Vries et al., 2017; Pahl-Wostl, 2006; Pahl-Wostl et al., 2007a; Tippett et al., 2005).

\section{Conclusion}

In this study, we analyzed how trust and shared group identities shaped processes occurring within learning spaces and influenced transboundary basin cooperation processes in the Zambezi basin. We 


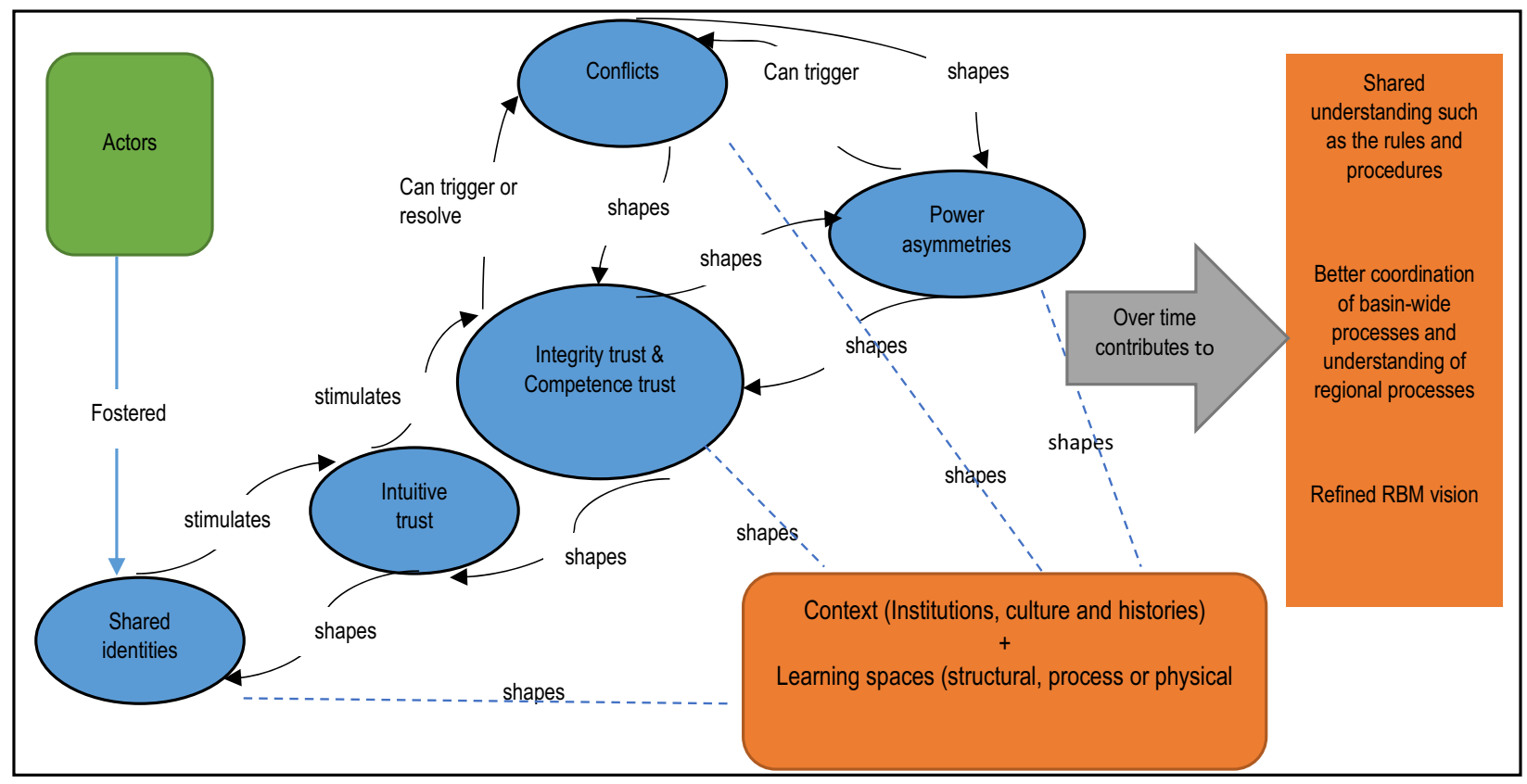

Fig. 4 Learning space in the Zambezi basin. Shows interaction of trust, shared identities and learning spaces in the Zambezi basin (source own).

incorporated literature on social learning, trust, social identity and communities of practice to form the conceptual framework. We evaluated social learning processes through the concept of learning spaces (arenas for interaction, deliberation and reframing). Our results show that trust and shared group identities are interrelated and had a crucial impact on the interactions among actors in the Zambezi basin and in turn influenced transboundary river basin cooperation. Further, we find that a decline in trust stagnated social learning processes. The results demonstrate that leveraging on shared group identities can play a critical role in stimulating trust among actors and in turn stimulate cooperation processes. However, it is not a guarantee for cooperation due to the dynamic nature of relational features. Further, we found that learning spaces such as processlearning spaces (regional integration), structural-learning spaces (ZAMCOM and tools for information and data management) and physical-learning spaces (ZBSF) stimulated a change in understanding of basin management processes among actors over time thus, they are crucial in fostering social learning.

Overall, this study advances the social learning literature by accounting for relational features such as trust and shared group identities in social learning processes. Such an understanding may explain some of the dynamics in social learning processes and outcomes. For practitioners in transboundary water management processes, facilitating trust among actors could benefit from understanding the drivers of trust and attributes of shared group identities and leveraging on them. In the Zambezi basin, strengthening water cooperation could include understanding the drivers for sub-basin cooperation in areas of trade, tourism or infrastructural development. In deliberative processes, focus should be put on creating environments that foster trust and nurture shared identities in order to further stimulate social learning processes such as transparency in data sharing, active participation in decision-making processes or structures that support inclusivity and equity among actors. This study highlights as well the importance of institutionalization at a more advanced state of social learning. Structurallearning spaces support the development of binding commitments and enduring shared practices. However, success of such institutionalization is strongly influenced by the prior development of trust and a shared social identity.
This study has added value because few studies have evaluated relational features in emergent social learning process, thus, we provide a deeper understanding of social-learning processes. We found the concept of learning space useful to conceptualize sociallearning processes and provide a structured approach to evaluate learning. Therefore, a deeper understanding of relational features (such as trust and identity), and the learning space could contribute new insights into the concept of social learning. To conclude, followup studies could explore other relational features such as power in social-learning processes. Additionally, further research could benefit from testing the conceptual framework in deliberative learning processes and other case studies. In addition, the study was limited in the sample of interviews conducted thus relied on data from literature reviews, as such, future research could include a wider sample of stakeholders to be interviewed. While each context may vary, we hope the results from this study can provide a better understanding of multi-stakeholder and social-learning processes in other natural resources management processes.

\section{Data availability}

The datasets analyzed during the current study are not publicly available due to confidentiality reasons but are available from the corresponding author on reasonable request.

Received: 28 December 2019; Accepted: 11 November 2020; Published online: 09 December 2020

\section{Notes}

1 Ubuntu is an African philosophy originating from Southern Africa that refers to: "I am because we are" (see Mabovula, 2011).

2 Zambezi Action Plan Project, proposed UNEP projects initiated by SADC.

3 ZAMSEC, short for ZAMCOM secretariat.

\section{References}

Baird J, Plummer R, Haug C, Huitema D (2014) Learning effects of interactive decision-making processes for climate change adaptation. Glob Environ Chang 27:51-63. https://doi.org/10.1016/j.gloenvcha.2014.04.019 
Berkes F (2009) Evolution of co-management: role of knowledge generation, bridging organizations and social learning. J Environ Manage 90:1692-1702. https://doi.org/10.1016/j.jenvman.2008.12.001

Boeije H (2002) A Purposeful approach to the constant comparative method in the analysis of qualitative interviews. Qual Quant 36:391-409

Boschetti F, Cvitanovic C, Fleming A, Fulton E (2016) A call for empirically based guidelines for building trust among stakeholders in environmental sustainability projects. Sustain Sci 11:855-859. https://doi.org/10.1007/s11625-016$0382-4$

Bridge G (2009) Material worlds: natural resources, resource geography and the material economy. Geogr Compass 3:1217-1244. https://doi.org/10.1111/ j.1749-8198.2009.00233.x

Burke PJ (2004) Identities and social structure: The 2003 Cooley-Mead Award address. In: Social Psychology Quarterly. American Sociological Association, pp. 5-15

Cook P (1999) I heard it through the grapevine: making knowledge management work by learning to share knowledge, skills and experience. Ind Commer Train 31:101-105. https://doi.org/10.1108/00197859910269185

Cundill G, Harvey B, Tebboth M, et al. (2018) Large-Scale transdisciplinary collaboration for adaptation research: challenges and insights. Glob Challenges 1700132. https://doi.org/10.1002/gch2.201700132

Cundill G, Rodela R (2012) A review of assertions about the processes and outcomes of social learning in natural resource management. J Environ Manage 113:7-14. https://doi.org/10.1016/j.jenvman.2012.08.021

Cundill G, Harvey B (2019) Unpacking the potential role of social learning in adaptation policy. In: Keskitalo ECH, Preston BL (Ed.) Research handbook on climate change adaptation policy. Edward Elgar Publishing, Cheltenham, UK; Northampton, USA, pp. 125-137

Daniels SE, Walker GB (1996) Collaborative learning: improving public deliberation in ecosystem-based management. Environ Impact Assess Rev 16:71-102. https://doi.org/10.1016/0195-9255(96)00003-0

Das B, Fernández CF, van der Gaag N, et al. (2016) Water integrity global outlook. Water Integrity Network Association e.V. (WIN), Berlin

de Vries J, van Bommel S, Blackmore C, Asano Y (2017) Where there is no history: how to create trust and connection in learning for transformation in water governance. Water 9:130. https://doi.org/10.3390/w9020130

Engelbrecht AS, Heine G, Mahembe B (2017) Integrity, ethical leadership, trust and work engagement. Leadersh Organ Dev J 38:368-379. https://doi.org/ 10.1108/LODJ-11-2015-0237

Eriksson M, van Riper CJ, Leitschuh B, et al. (2019) Social learning as a link between the individual and the collective: evaluating deliberation on social values. Sustain Sci 14:1323-1332. https://doi.org/10.1007/s11625-019-00725-5

Eshuis J, Stuiver M (2005) Learning in context through conflict and alignment: farmers and scientists in search of sustainable agriculture. Agric Human Values 22:137-148. https://doi.org/10.1007/s10460-004-8274-0

Folke C, Hahn T, Olsson P, Norberg J (2005) Adaptive governnace of socialecological systems. Annu Rev Environ Resour 30:441-473. https://doi.org/ 10.1146/annurev.energy.30.050504.144511

Francisco de Oliveira G, Rabechini R (2019) Stakeholder management influence on trust in a project: a quantitative study. Int J Proj Manag 37:131-144. https:// doi.org/10.1016/j.ijproman.2018.11.001

Handley K, Sturdy A, Fincham R, Clark T (2006) Within and beyond communities of practice: making sense of learning through participation, identity and practice. J Manag Stud 43:641-653. https://doi.org/10.1111/j.14676486.2006.00605.x

Harrington C, Curtis A, Black R (2008) Locating communities in natural resource management. J Environ Policy Plan 10:199-215

Hartman F (2002) The role of trust in project management. In: Slevin D, Cleland D, Pinto J (eds) The frontiers of project management. Project Management Institute, Newtown Square, pp. 225-35

Herrero P, Dedeurwaerdere T, Osinski A (2019) Design features for social learning in transformative transdisciplinary research. Sustain Sci 14:751-769. https:// doi.org/10.1007/s11625-018-0641-7

Jans L, Postmes T, Van der Zee KI (2011) The induction of shared identity: the positive role of individual distinctiveness for groups. Personal Soc Psychol Bull 37:1130-1141. https://doi.org/10.1177/0146167211407342

Karlsen JT, Græe K, Massaoud MJ (2008) Building trust in project-stakeholder relationships. Balt J Manag 3:7-22. https://doi.org/10.1108/17465260810844239

Keen M, Brown VA, Dyball R (2005) Social learning in environmental management: towards a sustainable future. Routledge, London

Lacey J, Howden M, Cvitanovic C, Colvin RM (2018) Understanding and managing trust at the climate science-policy interface. Nat Clim Chang 8:22-28. https://doi.org/10.1038/s41558-017-0010-z

Lautze J, Phiri Z, Smakhtin V, Saruchera D (2017) The Zambezi river basin: water and sustainable development. Taylor and Francis

Lebel L, Grothmann T, Siebenhüner B (2010) The role of social learning in adaptiveness: insights from water management. Int Environ Agreements Polit Law Econ 10:333-353. https://doi.org/10.1007/s10784-010-9142-6
Leeuwis C (2000) Reconceptualizing participation for sustainable rural development: towards a negotiation approach. Dev Change 31:931-959. https://doi org/10.1111/1467-7660.00184

Lukes S (2005) Power: a radical view. Palgrave Macmillan

Lumosi CK, Pahl-Wostl C, Scholz G (2019) Can "learning spaces" shape transboundary management processes? Evaluating emergent social learning processes in the Zambezi basin. Environ Sci Policy 97. https://doi.org/10.1016/j. envsci.2019.04.005

Mabovula NN (2011) The erosion of African communal values: a reappraisal of the African Ubuntu philosophy. J Human Soc Sci 3(1):38-48

Mostert E, Pahl-Wostl C, Rees Y, et al. (2007) Social learning in European riverbasin management: barriers and fostering mechanisms from 10 river basins. Ecol Soc 12:art19. https://doi.org/10.5751/ES-01960-120119

Muro M, Jeffrey P (2008) A critical review of the theory and application of social learning in participatory natural resource management processes. J Environ Plan Manag 51:325-344. https://doi.org/10.1080/09640560801977190

Nass C (1994) Knowledge or skills: which do administrators learn from experience? Organ Sci 5:38-50. https://doi.org/10.1287/orsc.5.1.38

Neville F, Reicher S (2011) The experience of collective participation: shared identity, relatedness and emotionality. Contemp Soc Sci 6:377-396. https:// doi.org/10.1080/21582041.2012.627277

Owens TJ, Robinson DT, Smith-Lovin L (2010) Three faces of identity. Annu Rev Sociol 36:477-499. https://doi.org/10.1146/annurev.soc.34.040507.134725

Pahl-Wostl C (2006) The importance of social learning in restoring the multifunctionality of rivers and floodplains. Ecol Soc 11:art10

Pahl-Wostl C, Craps M, Dewulf A, Mostert E, Tabara D, Taillieu T (2007a) Social learning and water resources management. Ecol Soc 12(2):5. http://www. ecologyandsociety.org/vol12/iss2/art5/

Pahl-Wostl C, Hare M (2004) Processes of social learning in integrated resources management. J Community Appl Soc Psychol 14:193-206. https://doi.org/ $10.1002 /$ casp.774

Pahl-Wostl C, Mostert E, Tàbara D (2008) The growing importance of social learning in water resources management and sustainability science. Ecol Soc 13(1):13

Pahl-Wostl C, Sendzimir J, Jeffrey P, et al. (2007b) Managing change toward adaptive water management through social learning. Ecol Soc 12:art30. https://doi.org/10.5751/ES-02147-120230

Pelling M, High C, Dearing J, Smith D (2008) Shadow spaces for social learning: a relational understanding of adaptive capacity to climate change within organisations. Environ Plan A 40:867-884. https://doi.org/ 10.1068/a39148

Pinto JK, Slevin DP, English B (2009) Trust in projects: an empirical assessment of owner/contractor relationships. Int J Proj Manag 27:638-648. https://doi.org/ 10.1016/j.ijproman.2008.09.010

Reed M, Evely A, Cundill G, et al. (2010) What is social learning? Ecol Soc 15:r1. https://doi.org/Article

Reicher S, Spears R, Haslam SA (2010) The social identity approach in social psychology. In: Wetherell MS, Mohanty CT (eds) Sage Identities Handbook. Sage, London, pp. 45-62

Ridder D, Mostert E, Wolters H (2005) Learning together to manage together. Involving participation in water management. Univ. Osnabrück, Inst. of Environmental Systems Research

Rist S, Chidambaranathan M, Escobar C, Wiesmann U, Zimmermann A (2007) Moving from sustainable management to sustainable governance of natural resources: the role of social learning processes in rural India, Bolivia and Mali. J Rural Stud 23:23-37. https://doi.org/10.1016/j.jrurstud.2006.02.006

Rodela R (2013) The social learning discourse: trends, themes and interdisciplinary influences in current research. Environ Sci Policy 25:157-166. https://doi.org/ 10.1016/j.envsci.2012.09.002

Romina R (2014) Social learning, natural resource management, and participatory activities: a reflection on construct development and testing. NJASWageningen J Life Sci 69:15-22. https://doi.org/10.1016/j.njas.2014.03.004

Rousseau DM, Sitkin SB, Burt RS, Camerer C (1998) Not so different after all: a cross-discipline view of trust. Acad Manag Rev 23:393-404. https://doi.org/ 10.5465/AMR.1998.926617

Saruchera D, Lautze J, Mwale J, et al. (2017) Transboundary water cooperation: taking stock and looking forward. In: Jonathan L, Phiri Z, Vladimir S, Saruchera D (eds) The Zambezi river basin: water and sustainable development. pp. 175-192

Scholz G, Methner N (2019) A social learning and transition perspective on a climate change project in South Africa. Environ Innov Soc Transitions https://doi.org/10.1016/j.eist.2019.10.011

Schusler TM, Decker DJ, Pfeffer MJ (2003) Social learning for collaborative natural resource management. Soc Nat Resour 16:309-326. https://doi.org/10.1080/ 08941920390178874

Sol J, Beers PJ, Wals AEJ (2013) Social learning in regional innovation networks: trust, commitment and reframing as emergent properties of interaction. J Clean Prod 49:35-43. https://doi.org/10.1016/j.jclepro.2012.07.041 
Stryker S, Owens TJ, Timothy J, White RW (eds) (2000) Self, identity, and social movements. University of Minnesota Press

Suškevičs M, Hahn T, Rodela R (2019) Process and contextual factors supporting action-oriented learning: a thematic synthesis of empirical literature in natural resource management. Soc Nat Resour 32:731-750. https://doi.org/ $10.1080 / 08941920.2019 .1569287$

Tajfel H (1982) Social psychology of intergroup relations. Annu Rev Psychol 33:1-39

Tajfel H, Turner J (1979) An integrative theory of inter-group conflict. In: Austin WG, Worchel S (eds) The social psychology of inter-group relations. Brooks/ Cole, Monterey, CA, pp. 33-47

Tippett J, Searle B, Pahl-Wostl C, Rees Y (2005) Social learning in public participation in river basin management-Early findings from HarmoniCOP European case studies. Environ Sci Policy 8:287-299. https://doi.org/10.1016/ j.envsci.2005.03.003

Turner JC, Hogg MA, Oakes PJ, et al. (1987) Rediscovering the social group: a selfcategorization theory. Basil Blackwell, Oxford and New York, NY

Van Bommel S, Röling N, Aarts N, Turnhout E (2009) Social learning for solving complex problems: a promising solution or wishful thinking? A case study of multi-actor negotiation for the integrated management and sustainable use of the drentsche aa area in the Netherlands. Environ Policy Gov 19:400-412. https://doi.org/10.1002/eet.526

Watson N (2004) Integrated river basin management: a case for collaboration. Int J River Basin Manag 2:243-257. https://doi.org/10.1080/15715124.2004.9635235

Wenger E (1998) Communities of practice: learning, meaning, and identity. Cambridge University Press

Yin RK (2014) Case study research: design and methods, 5th edn. Sage Publications, California

\section{Acknowledgements}

The field work for this study was funded by the DAFNE project, as part of the Horizon 2020 program of the European Union, Grant number 690268. Open Access funding enabled and organized by Projekt DEAL.

\section{Funding}

Open Access funding enabled and organized by Projekt DEAL.

\section{Competing interests}

The authors declare no competing interests.

\section{Additional information}

Supplementary information is available for this paper at https://doi.org/10.1057/s41599020-00669-7.

Correspondence and requests for materials should be addressed to C.K.L.

Reprints and permission information is available at http://www.nature.com/reprints

Publisher's note Springer Nature remains neutral with regard to jurisdictional claims in published maps and institutional affiliations.

(c) (i) Open Access This article is licensed under a Creative Commons Attribution 4.0 International License, which permits use, sharing, adaptation, distribution and reproduction in any medium or format, as long as you give appropriate credit to the original author(s) and the source, provide a link to the Creative Commons license, and indicate if changes were made. The images or other third party material in this article are included in the article's Creative Commons license, unless indicated otherwise in a credit line to the material. If material is not included in the article's Creative Commons license and your intended use is not permitted by statutory regulation or exceeds the permitted use, you will need to obtain permission directly from the copyright holder. To view a copy of this license, visit http://creativecommons.org/ licenses/by/4.0/.

(C) The Author(s) 2020 